\title{
ВЫПУСКНАЯ КВАЛИФИКАЦИОННАЯ РАБОТА КАК ОСНОВНОЙ МЕТОД ИССЛЕДОВАТЕЛЬСКОЙ КОМПЕТЕНТНОСТИ СОВРЕМЕННОГО СПЕЦИАЛИСТА
}

Одной из основных проблем экономики Республики продолжает оставаться проблема кадрового потенциала. Профессиональное образование отличается от общего четкостью в определении образовательного результата, являющегося отражением социального заказа. Обучение в условиях реализации профессионального образования должно носить прогностический характер и формировать качества личности, которые потребуются выпускнику в будущем.

Одной из главных задач среднего медицинского образования является формирование компетентной личности, способной к саморазвитию, самообразованию, инновационной деятельности. Решение этой непростой задачи вряд ли возможно только путем передачи знаний в готовом виде от преподавателя к студенту. Необходимо в первую очередь перевести студента из пассивного потребителя знаний в активного их творца, умеющего сформулировать проблему, проанализировать пути ее решения, найти способ разрешения проблемы и доказать ее правильность. В результате чего, самообразование студентов становится не просто важной формой образовательного процесса, а основой в подготовке специалиста среднего звена[2]. Усиление роли саморазвития студентов означает принципиальный пересмотр организации учебновоспитательного процесса в СПО, который должен строиться так, чтобы развивать умение учиться, формировать у студента способности к творческому применению полученных знаний, способам адаптации к профессиональной деятельности в современном мире.

\section{ЦЕЛЬРАБОТ Ы}

Проанализировать специфику исследовательской работы будущего медицинского специалиста среднего звена, выявить основные направления исследований и их значение для практического здравоохранения.
Выпускная квалификационная работа (далее BКР) представляет собой систематизацию разноплановых знаний, полученных студентом за весь период обучения в колледже и является законченным самостоятельным исследованием студента, связанным с решением определенных задач в профессиональной области.

Написание студентом выпускной работы это особый вид познавательной деятельности, сложная интеллектуальная задача. От студентавыпускника требуется не только высокий уровень общих и профессиональных компетенций, эрудиции, но и умение соответствующим образом излагать свои мысли в письменной форме, правильно организовать свое исследование. Целью исследовательской части выпускной работы является демонстрация знаний и умений студента применять методы научного исследования для решения практических проблем, возникающих в деятельности медицинского учреждения.

\section{МАТЕРИАЛ И МЕТОДЫ}

Исследования в сестринском деле - одно из новых направлений развития и формирования компетентностей современного студента медицинского колледжа и будущего специалиста [1]. Анализ подтверждает качественные изменения в системе образования и дальнейшей профессиональной деятельности при оказании медицинской помощи населению в связи с внедрением сестринских исследований (повышение удовлетворённости пациентов, сокращение сроков пребывание в стационаре, уменьшение числа осложнений и т.д.).

Условно можно выделить три направления исследований в выпускных квалификационных работах.

(c) О.В. Швыдкий, Е.Н. Тарасенко, Н.П. Паниева, 2019 (c) Университетская Клиника, 2019 
Первое направление - определение роли среднего медицинского работника в лечении и уходе за пациентом при каком-либо заболевании и состоянии.

Цель работы - осуществить сестринский процесс при уходе за конкретным пациентом.

Практическая часть - обследование пациента, выявление проблем пациента, составление индивидуального плана ухода с учетом особенностей пациента (сопутствующее заболевание, эмоционально-психическое состояние) на основе стандартного плана, реализация плана ухода (прикладывается дневник наблюдения за пациентом не менее чем в течение 10 дней), оценка эффективности вашей работы.

Второе направление - изучение мнения/ уровня знаний пациентов по каким-либо медицинским вопросам (классическая исследовательская работа).

Цель работы - выявить уровень знаний по какому-либо вопросу и составить рекомендации для пациентов.

Практическая часть - составить анкету для пациентов, провести анализ анкетирования, определить возможные причины дефицита знаний, составить рекомендации для пациентов.

Третье направление - изучение новых методик, технологий лечения и ухода за пациентом, нового медицинского оборудования.

Цель работы - изучить новую методику/технологию/оборудование и подготовить учебный видеофильм.

Практическая часть - описать методику/технологию/оборудование, сравнить с применяемыми/используемыми ранее или применяемыми в других медицинских организациях, выявить преимущества, подготовить учебный видеофильм [2].

Данное коммуникативное умение не может появиться само собой, без специальных усилий студента в период обучения и должно осуществляться под контролем руководителя ВКР.

Руководитель, как правило, определяет: направление исследования, помогает сформулировать тему, цель, задачи, гипотезу. Оказывает помощь студенту в подборе необходимой литературы и разработке плана практической части.

При выполнении исследовательской работы студент должен продемонстрировать следующие умения и знания:

- самостоятельно поставить исследовательскую задачу, оценить ее актуальность и социальную значимость;

- собрать и обработать информацию по теме исследования;
- изучить и критически проанализировать существующие материалы по проблеме работы;

- глубоко и всесторонне исследовать выявленную проблему;

- выработать, описать и профессионально аргументировать свои варианты решения рассматриваемой проблемы ВКР;

- сформулировать обоснованные выводы, предложения, рекомендации по внедрению полученных результатов в практическую деятельность среднего медицинского персонала.

\section{РЕЗУЛЬТАТЫ И ОБСУЖДЕНИЕ}

Чтобы исследовательская работа была успешной, тема исследования должна быть актуальна, касаться будущей профессиональной деятельности и отображать критическую позицию творческого мышления студента.

Для выбора темы исследовательской работы внимание должно быть направлено на анализ эффективности использования рабочего времени, качество медицинской помощи, общественное мнение по поводу каких-либо процессов и явлений современной медицины, межличностных отношений медицинского персонала, состояния здоровья медицинского персонала и т.д.

Так, среди тем ВКР в 2017-2018 учебном году можно выделить следующие: «Обучающая роль медицинской сестры в ведении пациентов с гипотиреозом», «Обучающая роль медицинской сестры пациентов с хроническим пиелонефритом как необходимое условие повышения эффективности лечебно-диагностического процесса», «Особенности сестринского процесса у пациентов с железодефицитной анемией», «Анализ состояния здоровья детей на курируемом участке», «Значение школы здоровья для улучшения качества жизни больного сахарным диабетом», «Изучение ассортимента функциональных продуктов в г. Харцызске», «Вредные привычки среди студенческой молодежи. Изучение проблемы», «Анализ методов контрацепции, используемые женщинами фертильного возраста», «Роль акушерки в профилактике невынашивания беременности» и другие.

Выпускные квалификационные работы, написанные в нашем учебном заведении, можно использовать в качестве дополнительного материала, рекомендаций для студентов, пациентов, медицинских работников лечебнопрофилактических учреждений. Лучшие выпускные квалификационные работы, представляющие практическую ценность, могут быть использованы в качестве наглядных пособий и рекомендаций, памяток в Республиканском и го- 
родских центрах «Здоровье», в кабинетах доклинической практики[3].

Важнейшей задачей сестринского дела является достижение наивысшей эффективности и качества сестринской помощи населению. Для реализации этой сложной задачи, повышения профессионального и социального статуса сестринского дела необходимо создание базы научных знаний, составляющих основу профессиональной сестринской практики.

\section{З А К ЛЮЧЕНИЕ}

Таким образом, сестринские исследования и участие в них студентов нашего колледжа необходимы для совершенствования сестринской практики, повышения качества медицинской помощи населению и признания уникальной роли сестринской профессии.

Участие в исследовательской работе дает воз- можность каждому студенту определить свои дальнейшие планы, приобрести необходимые исследовательские навыки и выступать с результатами своих изысканий на конференциях, семинарах, участвовать в дебатах.

В заключении следует отметить, что исследовательская работа рассматривается как фактор, способствующий развитию учебноисследовательских умений студентов, помогает совершенствовать профессиональную компетентность будущего специалиста, способствует созданию системы теоретических знаний и практических умений, позволяет формировать отношение к науке как важнейшему средству диагностики, проектирования, прогнозирования и совершенствования практики в соответствии требованиям государственного образовательного стандарта.

\section{О.В. Швыдкий, Е.Н. Тарасенко, Н.П. Паниева}

ГПОУ «Донецкий медицинский колледж», Донецик

\section{ВЫПУСКНАЯ КВАЛИФИКАЦИОННАЯ РАБОТА КАК ОСНОВНОЙ МЕТОД ИССЛЕДОВАТЕЛЬСКОЙ КОМПЕТЕНТНОСТИ СОВРЕМЕННОГО СПЕЦИАЛИСТА}

В статье раскрывается сущность исследовательской работы при написании выпускной квалификационной работы, как условие развития и формирования компетентностей современного студента медицинского колледжа и будущего специалиста. Приводится последовательность проведения исследования и принципы, на которых должно основываться развитие исследовательских навыков у студентов. Делается вывод, что исследовательская работа способствует созданию системы теоретических знаний и прак- тических умений, позволяет формировать отношение к науке как важнейшему средству диагностики, проектирования, прогнозирования и совершенствования практики в соответствии с требованиями государственного образовательного стандарта.

Ключевые слова: выпускная квалификационная работа, исследовательская работа, сестринское исследование, профессиональные компетенции, самообразование, саморазвитие.

\section{O.V. Shvydkiy, E.N. Tarasenko, N.P. Panieva}

Donetsk medical college, Donetsk

\section{FINAL QUALIFYING WORK AS A BASIC METHOD OF RESEARCH COMPETENCE OF THE MODERN SPECIALIST}

The article reveals the essence of research work in writing the final qualifying work as a condition for the development and formation of the competencies of a modern student of a medical college and a future specialist. The stages of the research and the principles of students' research skills development are presented. It is concluded that research work contributes to the creation of a system of theoretical knowledge and practical skills, al- lows to form an attitude towards science as an important means of diagnostics, design, prognosis and improvement of practice in accordance with the requirements of the state educational standard.

Key words: final qualifying work, research work, nursing research, professional competence, self-education, self-development. 


\section{ЛИТЕРАТУРА}

1. Безрукова В.С. Педагогика. Проективная педагогика. Екатеринбург: Деловая книга; 2015. 344.

2. Боярский С.Г. Концепция развития российского здравоохранения: проблемы обеспечения кадрами в сфере организации здравоохранения и общественного здоровья. Медицинские технологии. Оценка и выбор. 2010; 2: 54-58.

3. Вишневский А.Г., Кузьминов Я.И., Шевский В.И., Шейман И.М., Шишкин С.В., Якобсон Л.И., Ясин Е.Г. Российское здравоохранение: как выйти из кризиса. Доклад Государственного университета Высшей школы экономики. М.: Издательский дом ГУ-ВШЭ, 2006. 25.

\section{REFERENCES}

1. Bezrukova V.S. Pedagogika. Proektivnaya pedagogika. Ekaterinburg: Delovaya kniga; 2015. 344.

2. Boyarskii S.G. Kontseptsiya razvitiya rossiiskogo zdravookhraneniya: problemy obespecheniya kadrami $\mathrm{v}$ sfere organizatsii zdravookhraneniya i obshchestvennogo zdorov'ya. Meditsinskie tekhnologii. Otsenka i vybor. 2010; 2: 54-58.

3. Vishnevskii A.G., Kuz'minov Ya.I., Shevskii V.I., Sheiman I.M., Shishkin S.V., Yakobson L.I., Yasin E.G. Rossiiskoe zdravookhranenie: kak vyiti iz krizisa. Doklad Gosudarstvennogo universiteta Vysshei shkoly ekonomiki. M.: Izdatel'skii dom GU-VShE, 2006. 25. 